\title{
Warming mattresses for newborns: effectiveness and risks
}

\author{
Jean-Pierre Libert, Stéphane Delanaud and Véronique Bach
}

Centre universitaire de recherche (CURS), Université de Picardie Jules Verne, France

Received: December 15, 2017; Published: December 19, 2017

*Corresponding author: Véronique Bach Peritox, Centre universitaire de recherche (CURS), Université de Picardie Jules Verne, Présidence, Chemin du Thil, F-80015 Amiens, France

\section{Abstract}

Premature and low-birth-weight newborns are particularly exposed to a risk of hypothermia. Warming techniques are therefore needed to maintain the newborn's body temperature. Warming mattresses provide external conductive heat and, if required, can be combined with other warming devices (such as radiant warmers and closed incubators). The present manuscript reviews the effectiveness of warming mattresses and the potential risks of hyperthermia when these mattresses are combined with other devices. It is essential to

a) standardize practice for this care technique within healthcare institutions, and

b) continuously measure the newborn's body temperature during mattress use.

Keywords: Newborn; Warming mattress; Hyperthermia; Hypothermia

\section{Introduction}

Homeothermy (corresponding to rectal temperature that remains between 36.5 and $37.5^{\circ} \mathrm{C}$ ) is optimal for extra-uterine survival. Body temperature control is particularly important for preterm and/or low-birth-weight newborns because their thermoregulatory processes are inefficient and their body heat losses to the environment are greater. Despite extensive research, the incidence of hypothermia among neonates is still high in developing countries, and remains a significant cause of short-and long-term morbidity and mortality. To prevent hypothermia during resuscitation and during transport from the delivery room to the neonatal intensive care unit, warming mattresses can be used to provide the neonate with conductive heat. This method of heat supply is often combined with other warming techniques (such as radiant warmers and closed incubators). It is important to ascertain the effectiveness and safety of warming mattresses because some cases of hyperthermia have been reported.

The greater the contact surface area between an infant's skin and the mattress, the greater the conductive heat exchange. Hence, conductive warming only occurs when the mattress's surface temperature is higher than that of the infant's skin. The mattress temperature must be maintained at between $35^{\circ} \mathrm{C}$ and $40^{\circ} \mathrm{C}$; at these temperatures, no cases of burns have been reported. A warming mattress can also supply radiant heat to skin surfaces that are not in direct contact with it. In a study of a black-painted copper manikin representing a small-for-gestational age neonate (body surface area: $0.086 \mathrm{~m}^{2}$; simulated bodyweight: $900 \mathrm{~g}$ ), lying in a convectively heated closed incubator (ISIS+ from Médipréma,
Tauxigny, France), Décima et al. [1] showed that the radiant energy provided by the mattress accounted for $42.9 \%$ of the body's radiant heat loss as a whole. The mattress can also generate a microclimate by increasing the temperature of the air above the infant, which reduces convective and evaporative heat losses. A warming mattress can be combined with a conventional incubator, a transport incubator and/or a radiant warmer. The addition of clothing and/or bedding increases the mattress's ability to warm a hypothermic infant but can also lead to hyperthermia if the clothing provides too much thermal insulation

\section{The Evaluation of Warming Mattresses}

A review of the literature in this field reveals that two types of studies have been performed. Firstly, anthropometric thermal manikins (i.e. physical models of the same size and shape as infants) have been used to precisely quantify the various heat exchanges involved (via conduction, convection and radiation; evaporative heat loss cannot be measured with this method). Secondly, a number of clinical studies of hypothermic or normothermic newborns of various ages have focused on either transport between the delivery room and the care department or the use of warming protocols in intensive care units. These experiments enable researchers to not only characterize a mattress's thermal performance but also to define the devices' conditions of use and requisite safety measures.

\section{Experiments on Thermal Manikins}

In 1984, LeBlanc [2] assessed the heat provided by a warming mattress with a rectangular polymethyl methacrylate tunnel 
placed above a heated manikin lying in a double-walled transport incubator (Model T167-13, Air Shields, Hatboro, WI, with the air temperature servo-control mode set to $35.6^{\circ} \mathrm{C}$ ) or in a single-walled transport incubator (airVac, Ohio Medical products, Madison, WI regulated in air mode at $36 \cdot 1^{\circ} \mathrm{C}$ ). A water-filled manikin (simulating a $1000 \mathrm{~g}$ newborn) made of thin plastic was heated so that it had an internal temperature of $37.0^{\circ} \mathrm{C}$ and a surface temperature of $36.8^{\circ} \mathrm{C}$. The room temperature ranged between 20 and $24^{\circ} \mathrm{C}$. The use of a warming mattress (Porta-Warm Mattress, Kay Laboratories, San Diego, CA, whose surface temperature did not exceed $40^{\circ} \mathrm{C}$ ) enabled a 3-5\% reduction in the incubator's heating power and an approximately $3^{\circ} \mathrm{C}$ reduction in the incubator's air temperature.

LeBlanc commented that the incubator's heating system had to be turned off 30 minutes after the warming mattress had been turned on, in avoid an excessively rapid increase in the manikin's temperature. 150 minutes after the start of the experiment, the incubator's air temperature had to be adjusted manually in order to stabilize the manikin's temperature at values similar to those measured during the baseline reference period. By extrapolating these observations to the infant, LeBlanc indicated that the use of a warming mattress makes it difficult to stabilize the body temperature. Hence, the use of an incubator with a skin servocontrol operating mode is preferable when a warming mattress is employed. In view of the interventions needed to stabilize the manikin's temperature, LeBlanc recommended that a warming mattress should only be used for hypothermic infants and/or when the incubator's heating system, the transport vehicle and the infant's clothing isolation are ineffective.

Sarman et al. [3] studied a plastic foam manikin (surface temperature set to $36.5^{\circ} \mathrm{C}$ ) as a model of a $1003 \mathrm{~g}$ infant wearing a nappy and a cotton vest and covered with two quilts. The manikin was placed on a water-filled mattress (Kanthal Medical Heating AB, Stockholm, Sweden, heated at four different surface temperatures between $35^{\circ} \mathrm{C}$ and $38^{\circ} \mathrm{C}$ ) inside in a single-walled incubator (Isolette C100, Air Shields, Pennsylvania) with an air temperature set to 30, 32,34 or $36^{\circ} \mathrm{C}$. All the experiments were performed in a climatic chamber at two different air temperatures $\left(25^{\circ} \mathrm{C}\right.$ and $15^{\circ} \mathrm{C}$; in the latter condition, a bonnet was placed on the manikin's head). The results showed that the manikin's heat loss was between 20 and $40 \mathrm{~W} / \mathrm{m}^{2}$ with a mattress temperature of between $36^{\circ} \mathrm{C}$ and $37^{\circ} \mathrm{C}$ and an air temperature of $25^{\circ} \mathrm{C}$. At $15^{\circ} \mathrm{C}$, the same heat loss was only observed when the manikin was wearing a bonnet and was covered with a quilt. When the difference between the skin surface temperature and the mattress temperature was $4^{\circ} \mathrm{C}$, Sarman et al. estimated that the conductive heat gain was $1.6 \mathrm{~W}$. The researchers considered that this was a non-negligible heat gain, since it corresponded to $53 \%$ of the $3 \mathrm{~W}$ of metabolic heat produced by an infant weighing $1500 \mathrm{~g}$.

\section{Clinical Studies}

Clinical studies of warming mattresses have varied greatly with regard to the body weight of the participating infants (from $800 \mathrm{~g}$ to $3000 \mathrm{~g}$ ), the incubator's temperature control mode (airor skin servo-controlled or sometimes not even specified) and the country (including developing countries in which nursing care differs from that in developed countries). The physiological parameters measured also differed from one study to another (e.g. oxygen consumption, body weight, and the axillary, rectal, and abdominal skin surface temperatures). The risks of hypothermia or hyperthermia were assessed with regard to the latter temperature values and (in some cases) the difference between rectal and mean skin temperatures (considered to be a marker of cold stress) [4]. Different warming mattresses are often used as an additional source of heat for infants at birth, regardless whether or not they are hypothermic. The mattress is often warmed up prior to use. The degree of clothing thermal insulation also differs from one study to another but is rarely specified. Thus, the data from these various studies are not comparable - making the results difficult to interpret.

Most of the literature data show that the warming mattress is an effective device for preventing hypothermia in preterm neonates. A notable exception is the study by Boo et al. [5], in which 71 out of 119 initially hypothermic neonates (axillary temperature: $36.5^{\circ} \mathrm{C}$ ) treated with a heated water-filled mattress (KanMed, Bromma, Sweden kept at a constant temperature of $37^{\circ} \mathrm{C}$; room air temperature: $20^{\circ} \mathrm{C}$ ) remained hypothermic. Nevertheless, the literature data have highlighted conditions in which the use of a warming mattress can be dangerous for the infant and cases of moderate hyperthermia are often reported [4,6-9]. L'Hérault et al. [6] reported that a greater proportion of neonates transported to hospital on a gel mattress (Prism technologies, San Antonio, TX) had rectal temperature of $\geq 37.5^{\circ} \mathrm{C}$ (and even $39^{\circ} \mathrm{C}$ in four cases) on arrival. Gray et al. [7] also reported that the proportion of individuals with high $\left(>37.5^{\circ} \mathrm{C}\right)$ axillary temperature was greater for neonates nursed on a heated, water-filled mattress (Kan Med Baby Warmer) in a cot than for those nursed in an air-heated incubator. In a resuscitation setting, Singh et al. [9] showed that the incidence of hyperthermia (axillary temperature $>37.5^{\circ} \mathrm{C}$ ) increased in neonates nursed on a gel mattress (Drager, Hemel Hempstead, UK) and wrapped in a food standard plastic bag (Lakeland Plastic, Windermere, UK) compared to traditional care including radiant warmer $(+27 \%)$ and to neonates only covered by the bag $(24 \%)$. The harmful effects of hyperthermia mean that this risk must be taken in consideration. Hence, the continuous measurement of the rectal, abdominal or axillary temperature is highly advisable for monitoring changes in an infant's thermal status.

\section{Implications for Practice and for Research}

When used alone, a warming mattress is not highly effective because little heat is gained by conduction. An older study [10] found that in cool environment, a warming mattress alone could not warm an unclothed, premature newborn. Most researchers have shown that a heated, water-filled mattress is not only effective for warming an infant dressed in a single cotton shirt and a diaper (room air temperature: $24.6^{\circ} \mathrm{C}$ ) but it can also reduce the resting oxygen consumption $(-3.1 \%)$ and the heart rate $(-3 \mathrm{bpm})$ [11]. Several publications have assessed the thermal performance of a mattress used with the neonate clothed and covered by blankets and placed in a cot [5,7,12-14] or in a sleeping bag [15]. The warming mattress has very often been combined with other heating devices 
used in routine thermal care including closed incubators $[6,10,16]$, hats, radiant warmers, plastic bags and plastic heat shields $[8,9,17$ 19].

Few publications have assessed the thermal performance of a mattress used alone on covered neonates [4, 20]. When the infant is covered (e.g. by clothing or a plastic heat shield), a microclimate is created between the covering and the infant's skin. The resulting increases in air temperature and relative humidity reduce radiant, convective and evaporative heat losses and thus accentuate the risk of hyperthermia. A mattress is of course more effective when the infant is covered, although the quantification of the thermal insulation provided by clothing and/or blankets is also an ongoing research topic. In the absence of values that enable one to assess the reduction in dry and latent heat exchanges between the infant and its environment, the use of a mattress to warm a covered infant is therefore imprecise. In any case, this procedure can never achieve the level of thermal control obtained in a closed incubator

In order to improve the thermal management of these patients, other factors must be taken into account. Simon et al. [16] assumed that a cool delivery room temperature might have been associated with inability to prevent hypothermia for 7 out of 17 neonates (41\%) nursed on an exothermic mattress and for 13 out of 19 neonates $(68 \%)$ wrapped in an occlusive polyethylene bag. The mother's body temperature [18] and, in particular, the infant's gestational age [6] should also be taken into account, although their influence on the occurrence of hyperthermia is subject to debate. It also appears to be necessary to standardize care procedures and warming techniques with regard to the neonate's body temperature measured at birth. Lastly, L'Hérault et al. [6] suggested that the warming rate should also be investigated; although it is sometimes stated that warming up the infant very rapidly is an advantage, the physiological effects of this procedure have not been characterized.

\section{Conclusion}

In view of the diverse range of settings and physiological measurements studied to date, one can conclude that the warming mattress is an easy-to-use means of warming ill or low-birth-weight newborns and is less costly than an incubator. The mattress creates less of a barrier between the mother and her baby than a closed incubator does [14]; this might reinforce mother-baby bonding and might therefore explain (at least in part) the increase in mother's milk production following discharge from hospital [14]. However, this hypothesis is subject to much debate [21], and needs to be analyzed on a broader scale in the future. Carers should be aware that some cases of hyperthermia have been linked to the use of a warming mattress - notably when the latter has been combined with other heating systems and/or the degree of clothing insulation is too high. Many researchers advise against the use of a warming mattress with thermally unstable or low-birth-weight infants [4,6$11,13,16,21]$.

The use of a warming mattress should thus always be accompanied by continuous monitoring of the infant's body temperature. Caring for premature newborns in open cots might also be associated with potential risks, such as the risk of nosocomial infection (due to easier access and greater handling by nursing staff and mothers). Although no cases of infection have reported in the literature, Gray et al.'s meta-analysis [21] indicated that further research on this topic is necessary. Although a warming mattress is a good option for the care of hypothermic infants in centers where warming techniques are limited, the impact of this device's long-term use remains to be determined. There is also a need to harmonize practice across care centers and thus ensure greater safety in use.

\section{References}

1. Décima P, Stéphan-Blanchard E, Ghyselen L, Delanaud S, Dégrugilliers L, et al. (2011) Assessment of radiant temperature in a closed incubator. Eur J Applied Physiol 112(8): 2957-2968.

2. LeBlanc M (1984) Evaluation of two devices for improving thermal control of premature infants in transport. Critical Care Med 12(7): 593595.

3. Sarman I, Bolin D, Holmér I, Tunell R (1992) Assessment of thermal conditions in neonatal care: use of a manikin of premature baby size. American Journal of Perinatology 9(4): 239-246.

4. Green-Abate C, Tafari N, Rao MR, Yu KF, Clemens JD (1994) Comparison of heated water-filled mattress and space-heated room with infant incubator in providing warmth to low birth weight newborns. International Journal of Epidemiology 23(6): 1226-1233.

5. Boo NY, Selvarani S (2005) Effectiveness of a simple water-filled mattress for the prevention and treatment of neonatal hypothermia in the labour room. Singapore Med J 46(8): 387-391.

6. L'Herault J, Petroff L, Jeffrey J (2001) the effectiveness of a thermal mattress in stabilizing and maintaining body temperature during the transport of very low- birth weight newborns. Applied Nursing Research 14(4): 210-219.

7. Gray PH, Paterson S, Finch G, Hayes M (2004) Cot-nursing using a heated, water-filled mattress and incubator care: a randomized clinical trial. Acta Paediatr 93(3): 350-355.

8. Almeida PG, Chandley J, Davis J, Harrigan RC (2009) Use of the heated gel mattress and its impact on admission temperature of very low birthweight infants. Advances in Neonatal Care 9(1): 34-39.

9. Singh A, Duckett J, Newton T, Watkinson M (2009) Improving neonatal unit admission temperatures in preterm babies: exothermic mattresses, polythene bags or a traditional approach? Journal of Perinatology p. 30(1): 45-49.

10. Nielsen HC, Jung AL, Atherton SO (1976) Evaluation of the Porta-Warm Mattress as a source of heat for neonatal transport. Pediatrics 58(4): 500-504.

11. Sarman I (1992) Thermal responses and heart rates of low-birth- weight premature babies during daily care on a heated, water-filled mattress. Acta Paediatr 81(1): 15-20.

12. Sarman I, Can G, Tunell R (1989) Rewarming preterm infants on a heated, water filled mattress. Archives of Disease in Childhood 64(5): 687-692.

13. Sarman I, Tunell R (1989) providing warmth for preterm babies by a heated, water filled mattress. Archives of Disease in Childhood 64(1): 29-33.

14. Sarman I, Tunell R, Västberg L, Carlquist U, Can G, et al. (1993) Mothers's perceptions of their preterm infants treated in an incubator or on a heated water-filled mattress: a pilot study. Acta Paediatr 82(11): 930933.

15. Bhat SR, Meng NF, Kumar K, Nagesh KN, Kawale A, et al. (2015) Keeping babies warm: a non-inferiority trial of a conductive thermal mattress. Arch Dis Child Fetal Neonatal 100(4): F309-F312.

16. Simon P, Dannaway D, Bright B, Krous L, Wlodaver A, et al. (2011) Thermal defense of extremely low gestational age newborns during 
resuscitation: exothermic mattresses vs polyethylene wrap. Journal of Perinatology 31(1): 33-37.

17. Topper WH, Stewart TP (1984) Thermal support for the very-low-birthweight infant: role of supplemental conductive heat. J Pediatrics 105(5): 810-814.

18. Chawla S, Amaram A, Gopal SP, Natarajan G (2011) Safety and efficacy of trans-warmer mattress for preterm neonates: results of a randomized controlled trial. Journal of Perinatology 31(12): 780-784.
19. McCarthy LK, Molloy EJ, Twomey AR, Murphy JFA, O’Donnell CPF (2013) A randomized trial of exothermic mattresses for pretherm newborns in polyethylene bags. Pediatrics 132(1): 135-141.

20. Hey EN, O'Connel B (1970) Oxygen consumption and heat balance in the cot-nursed baby. Archives of Disease in Childhood 45(241): 335-343.

21. Gray PH, Flenady V (2011) Cot-nursing versus incubator care for preterm infants. Cochrane Database Syst Rev Issue 8, art CD003062.

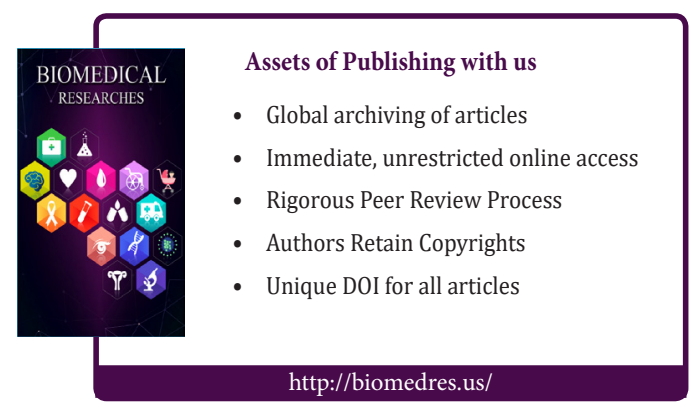

